\title{
The concept of community and the character of networks ${ }^{1}$
}

\author{
Michael Arnold \\ Dept. of History and Philosophy of Science, University of Melbourne, Australia \\ <mvarnold@unimelb.edu.au>
}

\begin{abstract}
Many case studies have examined Community Networks and we have at hand a good many rich and well grounded accounts of local experiences and outcomes as they have been observed in local circumstances. This sort of detailed, highly contextualized empirical work is essential to an understanding of contingent phenomena such as the performance of a Community Network. What we also need though, are theoretical approaches that are abstract enough to interpret the character and performance of differently situated Community Networks. The concept of community, the character of networks, and the implications of marrying the two, need to be teased out.

To this end, I suggest that Community Networks be understood analytically as a-modern hybrids that derive their ontological characteristics from a conflation of binaries. From this analytic perspective the Community Network is seen to be a sociotechnical assemblage that hybridizes the social and the technical, and not a set of technologies brought to bear on the social. The innovative feature of this particular form of sociotechnical assemblage, from an analytic point of view, is that it brings together "community" and "network" as both ontological concepts and as empirically observable phenomenon.

The characterization of the assemblage as a "community" but also as a "network" is thus critiqued, and the differences between these two abstractions are explored; and it is further argued, that the contrary ontology of the particular assemblage, manifest structures that are at once heterarchic as well as hierarchic.

The overarching purpose here is to address two problems: the neglect of theory and of abstractions in current ethnographic approaches, and the concomitant desire to develop theory and abstractions that are sensitive to the local and contingent nature of Community Networks. It is argued that an amodern approach fits both requirements in so far as it identifies key abstractions as binaries, and embraces the coexistence of these binaries rather than arbitrating between them..
\end{abstract}

\section{Introduction}

A geographically based Community Network will typically enable the residents of a particular locale to communicate with one another; organize in groups both traditional and novel; access on-line government and council services; participate in educational groups and cooperatives; create multimedia content; publish personal and local community content; participate in local e-commerce; share informational resources with other groups and communities; develop IT skills, and engage in all sorts of other activities. In short, Community Networks appropriate ICTs, and configure them for use by communities. Though the technology is less than a decade old, hundreds of geographically based Community Networks are operating in North America, scores are operating in Europe, and several are operating in Australia. Whilst Community Networks have typically been installed through the collaborative efforts of community organizations, resident groups, local government authorities, corporate sponsors, university based research groups, and welfare and educational agencies, in a more recent trend towards commercialization, property developers are also installing community networks in new urban development sites in the United States, Australia and other places. In my country, Australia, for example, property developers such as the Stonehenge Group, Urban Pacific, Delfin, the Docklands Authority, and Lend Lease, have installed Community Networks in both "green-field" and high-rise housing developments.

The commercial rationale may be described as modernist in so much as it seeks the commodification of community as one response to 'the information society', and the not-for-profit rationale may be described as modernist in so much as it seeks to shape the subject ( $a$ la Foucault) into a form of self-governing communitarianism, and engineer the selfgoverning community as a "progressive" project. The rationale for building these facilities (in the case of the not-forprofit sector), and for selling them (in the case of the commercial sector), therefore brings together a mix of romantic communitarianism and modernist techno-utopianism, all given new energy by the contested but near universally

1 An earlier version of this paper was read at the 2004 Community Network Analysis Conference, Building \& Bridging Community Networks: Knowledge, Innovation \& Diversity through Communication, Brighton, 2004. I would like to thank the delegates for their constructive criticisms. I also thank the anonymous reviewers for their thoughtful comments and suggestions. 
accepted imperatives for survival and prosperity that gather under the headings "information society" and "knowledge economy" (see Fig. 1).

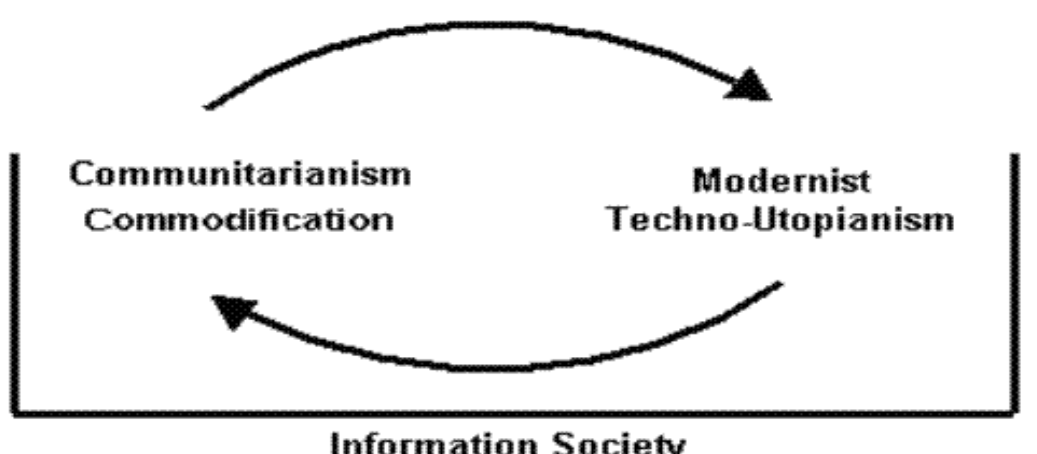

Fig. I The rationale for Community Networks

The techno-utopian and communitarian threads in the Community Network rationale are clear, and draw upon discourses that emphasize the role of technologies in securing a range of public goods. Whilst the great technologies of a previous era provided communities with piped water, sewerage systems, electrification and transport, so the technologies of the "information society" are providing an infrastructure for the public good. A glance through the Community Network literature will provide references to the role of contemporary technologies in establishing and maintaining bridging and bonding ties, learning communities, communities of practice, local and global connectedness, systems of trust, wider access to education and to employment opportunities, ameliorating the digital divide, facilitating civic engagement and social participation, and providing more efficient access to government services while enabling a more participatory form of democratic involvement. The centuries-old project of improving our social conditions through the employment of technology continues. In the case of the commercial Community Networks, all of this applies in equal measure, but there is also a parallel profit-seeking imperative that feeds into the need for product differentiation and market advantage in land and house sales. Here, the commercial utility of broadband, the cultural appeal of "high-tech modernity", the promise of differentiated access to informational resources, and above all, the very strong "saleability" of a "good neighborhood", and a "strong community" - packaged and delivered through ICTs suggests that Community Networks can commodify community, and can be important in the successful marketing of urban property developments.

An exegesis of the "information society" thesis and the substantial critique of that thesis mounted by Webster and others (F. Webster, 1994; Frank Webster, 1995), is beyond the scope of this paper, but the representation of our socioeconomic condition as being in some fundamental way information based, clearly provides a foundation for the Community Network project.

Case studies have examined many local examples of not-for-profit community intranets, and have provided wellgrounded accounts of their effect in the construction of community, the reconstruction of community, and the strengthening of community. In America, these accounts tend to be read in terms of social connections, social capital, and the on-going viability of traditional community institutions such as clubs, churches and school groups (see for example (Wellman, 1999; Wellman \& Haythornthwaite, 2002). In Britain, studies are more likely to be concerned with social equity variables - such as education, employment and health - as they present themselves in particular locales (Brixton, or Grimethorpe for example), or among an otherwise identifiable group (traveling people, single mothers and so on (Sherman, 1999). Studies that examine commercial systems are much less common (for exceptions see (Arnold, 2002, 2003; Arnold, Gibbs, \& Wright, 2003). The strength of all of these studies is their ethnographic detail, and their close focus on local sociological inputs and outcomes. But whilst valuable strategies emerge from these case studies such as the need to genuinely engage with existing community organizations on their own terms, to look for local champions for the system, and to cultivate local voices in decision making. A weakness in the research to date is the absence of theoretical models or abstractions that avoid the conceit of talking in terms of generalisable laws, but nevertheless retain the ambition of talking in terms of concepts that are appropriated from the indeterminate nature of contemporary networks, while remaining adaptable and robust enough to transfer across sites, and at the same time retaining analytic purchase.

\section{An A-modern Approach}

As Community Network research emerges as a more mature cross-disciplinary field, and builds from grounded case studies to integrative theory building, theoretical differences become more important to debate. To this end it is argued here that community networks be understood analytically as a-modern hybrids that derive their characteristics from a 
conflation of binaries.

That is to say, Community Networks are both technical devises and social arrangements; they invoke the identity of a network and a community, and manifest both hierarchic and heterarchic structures.

I think it is important not to dissolve these contradictions by arguing them through to middle ground, or by arbitrating between them and dismissing one of the alternatives as being "more true" or a more accurate representation than the other. Holding on to contradiction runs counter to the modernist episteme, which, over 250 years, has sought to dissolve contradiction and reach unambiguous clarity through the construction of three core binaries, and the privileging of one side of the binary in each case (Wise, 1997). These core binaries are, the bifurcation of time and space, (privileging time), subject and object, (privileging subject), and cause and effect, (privileging cause). Having made this crucial move, it becomes possible for the modernist to align either the technical or the social with cause, and its binary alternative with effect; either the machine, or the human, with subject, and its binary alternative with object; and either diachronic event sequences (time) or context (space) with cause, and its binary alternative with effect. In this bifurcation, some things are drivers and other things are passengers, some things lead and other things follow - when a more productive analytic strategy may be to resist the bifurcation altogether. Such a strategy is referred to here as "amodern".

I think that an understanding of Community Networks in particular, and our relationship with technology in general, is best pursued not by seeking to arbitrate opposing positions on the above, or by seeking middle ground compromises between opposing positions, but by attending to the tensions and stresses that emerge in the co-presence of contradictory forces. In this sense incoherence and inconsistency is important to maintain in an analysis that moves beyond the case study!

This attempt to analyse Community Networks in terms of conflated binaries, rather than through a simple empiricism, or through modernist dissolution or arbitration, draws upon an a-modern approach developed within Science and Technology Studies (STS) (B. Latour, 1993; Bruno Latour, 1999; J. Law \& Hassard, 1999), although, ironically, STS has also been criticised for an excessive dependence on case studies (Winner, 1993). As a discipline, STS began with studies of stirrups, microbes, bicycles, lathes, vacuum pumps and power stations, and has been further developed by studies of Brazilian rainforests, scallops, electric cars, cybernetic organisms, and African numbering systems. But in the course of following the heterogeneous engineers and actors of all kinds, as they seek to enrol one another, problematise goals, purify systems, create monsters, configure users, employ boundary objects, materialize imaginaries, and stabilize heterogeneous networks, Science and Technology Studies has moved our understanding, not just of our relationship with technology, but of the epistemological approaches to an understanding of our relationship with technology. Community Network studies have similarly relied on case studies that are strong empirically, but have not yet moved forward theoretically. The approach proposed in this paper falls short of this ambition, but gestures in that direction by drawing attention to some of the implications of this picture of a Community Network as a conflation of contradictions - as social and technical, a network and a community, and hierarchic and heterarchic. I begin with a discussion of the social and the technical.

\section{The Social and the Technical}

A Community Network assembles together a whole host of things - some of them commonly identified as social (community groups, individuals, commercial organizations, arms of government) and others commonly identified as technical (application software, web-servers, work stations). Having made a distinction that is so much part of the intellectual and cultural landscape as to pass unremarked, the technology can be placed front and centre in a privileged position. Of course, people involved with Community Networks are far too sophisticated to assume that ICTs of themselves are of particular benefit to communities, but still, it is the technology that is understood to be the facilitator, the catalyst, the cause of effects, the means to an end; it is the technology that we focus on, and that distinguishes the Community Network project from other community projects, and it is the social, read as the community in the "community network", that is the object of this facilitation ${ }^{2}$. The forementioned modernist separation and categorization of phenomena as either cause or effect is thus used to structure the relationship between technology and society (See Fig. 2).

2Although it is not the place to pursue it here, it doesn't really affect the argument if one chooses to reverse the respective roles of the social (community) and the technical (network). See (Bruno Latour, 1999) 


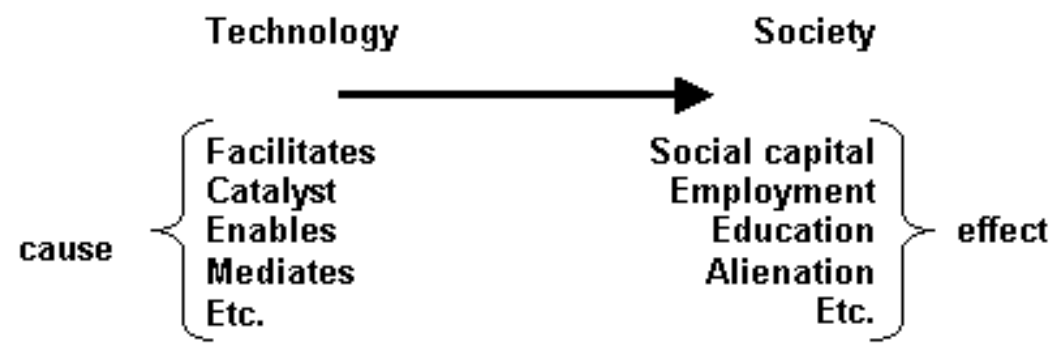

Fig. 2. technology drives progress

And so, from a global perspective, the World Summit on the Information Society is concerned with ameliorating the digital divide, and at the local level we are concerned with creating and sustaining Community Networks. Both take as their departure points an acceptance that ICT use is central to social advantage, and that social disadvantage is best addressed through ICT use (in preference to alternatives). Each accepts that use of high technology is normative, that it causes (facilitates, catalyses, mediates) positive outcomes, and a priori, non-use is a disadvantage to be remediated. The social disadvantage may be unemployment, or ill health or social isolation, but these are addressed through a filter that reads society as the information society, the economy as a knowledge economy, education as e-learning, health as medical informatics, and in all this, accepts the late modernist position that reads technology as the driver of progress. We thus work with technology and through technology to move the reality of our social existence closer and closer to the desires we have for that social existence (see Fig. 3).

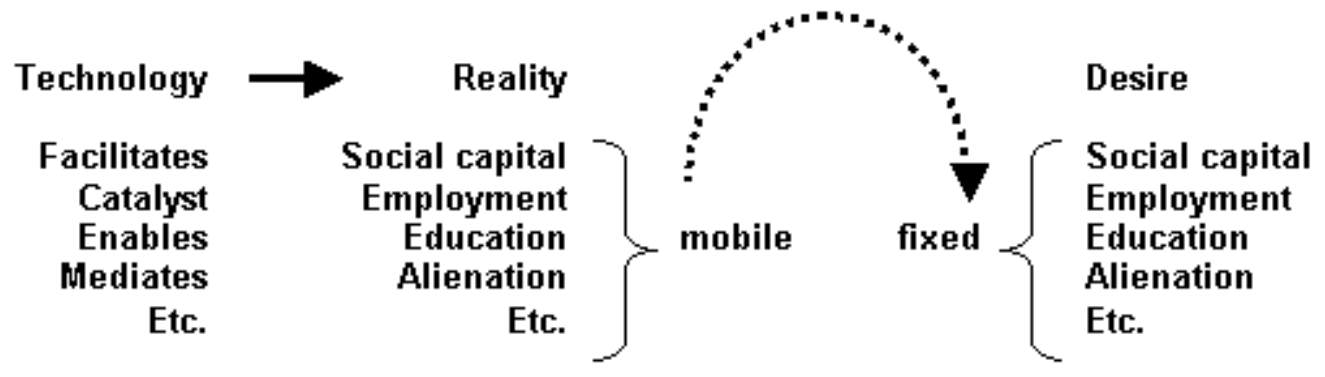

Fig. 3: the modernist paradigm; technology moves reality closer to desire.

A model that does not separate the technical from the social shifts the ground upon which we stand to think about the world, and advances our aforementioned project to be ambitious but not conceited. A given technology - TV, the production line, the Internet, the Community Network, is not a good thing for society (or community), nor a bad thing to be resisted. Rather, the hybridisation of the social and the technical changes the basis upon which we make a judgement about social goods and about outcomes. A Community Network is neither good nor bad for social connectedness, alienation, access to job markets, education, or whatever; rather, it changes what it is to be connected, alienated, in the job market, or educated. There is no ground that stands still to enable a pre and post assessment to be made. The question for researchers and practitioners then changes at all sites. The world is enframed in a different way. Reproductive technologies do not just provide a different means to the same end - they change our frame for situating maternity and paternity, and the ontology of mother, father, and family. Email doesn't provide a different means to the same end; it changes our frame for situating written correspondence. The mobile phone doesn't provide a different means to the same end, it changes our frame for situating mobility (in space) and fixity (in the space of flows), and what it is to be connected. Rather than assessing the "good" or "bad" effects of the technical on the social in terms of shifting reality closer to desire, one looks at how the ground is changing at this site as new sociotechnical assemblages cohabit the lifeworld and shift both reality and desire. The a-modern question is not how to assess and maximise the good use of ICTs in communities, but how ICTs in communities are changing what good is (see Fig. 4). 


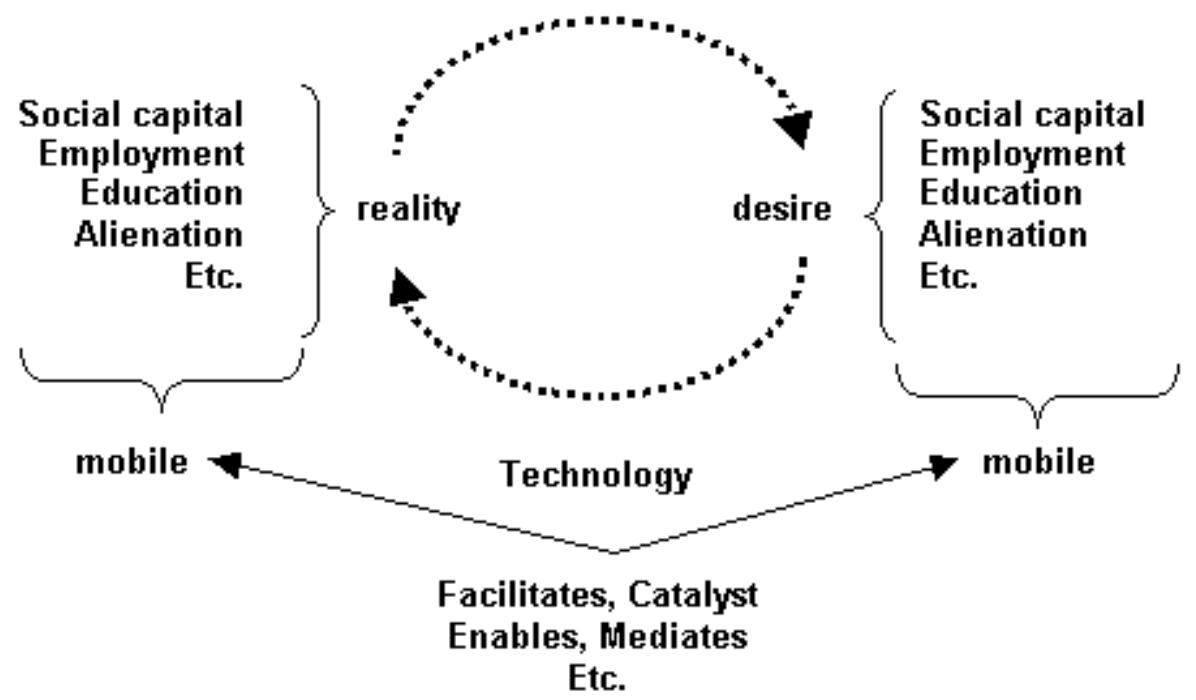

Fig. 4: the amodern paradigm; technology changes both reality and desire.

\section{The Network and the Community}

As Rheingold famously remarked, when a computer network is used for social purposes, it becomes a social network (Rheingold, 1993). The network metaphor, as used in the term "Community Network", invokes images of a web or net, whereby nodes (people and/or computers) are connected together to constitute a larger fabric - a larger entity in the sense that a local area network is a network, or the rail system is a network (see Fig. 5). The metaphor thereby foregrounds and privileges the connecting infrastructure rather than the nodes, or in modernist terms, the emphasis is on the "space" of connections, not the "time" of connecting.

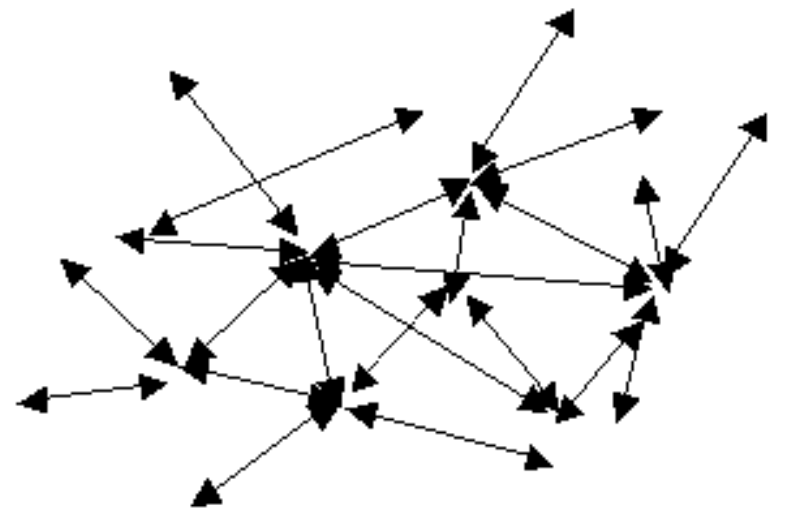

Fig. 5: community as a network.

But social networks are not composed of material links in the way computer networks, rail networks or electricity networks are. Our social performances are interactive, collective, responsive, but they are not connected by stable threads, tracks, lines or wires - though crucial to the Community Network metaphor, the Internet is nevertheless immaterial (Pollner, 2002). Our social performances (the community part of "Community Network") consist of a multitude of distributed, local, transient, quasi-independent acts - reflexive, reciprocal acts to be sure, but still, a collection of individual acts that only from an analytic perspective - not a phenomenological perspective - consist of something more structured. Despite the metaphor, a social network doesn't exist as an enduring material artifact, it is only there by virtue of a cascade of articulated sociotechnical performances that make it there, and will only be there so long as these actors choose to act. There are no lines between the nodes of the network, there are only the actions of the "nodes" - such as responding to email, posting to a list, attending a workshop, chatting in the corridor - that are patterned or structured in the abstract, not as specific material phenomena. The research emphasis is thereby on the social actors and their actions, and any connecting infrastructure recedes into the background. In modernist terms, the emphasis is on the "time" of action and reaction, not on the "space" of connecting infrastructure (see Fig. 6). 


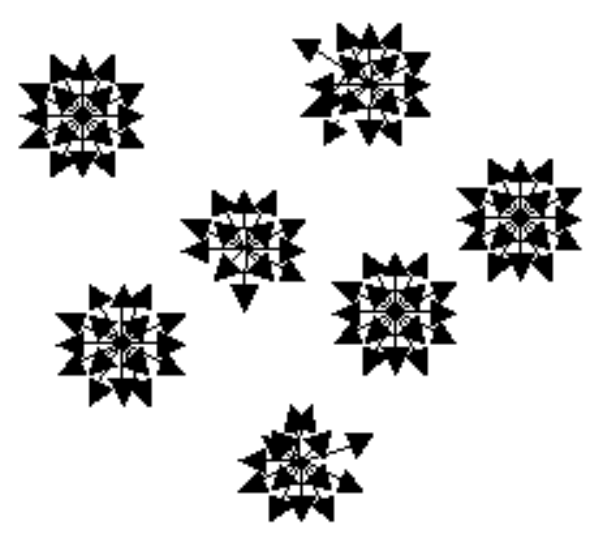

Fig 6: community as distributed performances.

Modernism thus throws up two visions of a community network, one emphasizing the structural links between nodes, the technical infrastructure in space; and the other emphasizing the performances of the nodes, the social interactions in time. I think it fair to say that most researchers in the field favour the latter 'social' model rather than the former 'determinist' model.

Two conclusions might be drawn in the context of researching Community Networks, if one accepts this.

Firstly, if the Community Network is built continuously by these acts, not by the community sector consortiums or property developers that engineer the network as infrastructure, and certainly not by the network as computer technology, the centre of attention is necessarily dispersed and distributed to the actors - to the network's multitudinous "nodes" - where the action begins and ends. The focus is on community networking (as a verb; a doing thing), rather than a Community Network (as a noun; an infrastructure thing). The ontology of community changes - from one that privileges space (an infrastructure, a context), to one that privileges time (events).

Secondly, if it is so that a sociotechnical network is the abstract reference to an ongoing cascade of individual acts, and not a network in the sense of a LAN or a railway, and these acts flow from the actors so to speak, not from space, then Wellman's argument contrasting social networks with community groups gains purchase (Wellman, 1999). A network in this context is not a community. A network is extensive, with indeterminate boundaries. A network is ramified and dynamically maintained through the repeated actions of loosely coupled individuals; it is not a default position. A network is transient and shape-changing - not historical. A network is created by the subjectivity of its members, not by the objectivity of any shared condition. From this perspective the Toennesian notion of a located Gemeinschaft community is outmoded, if indeed it ever applied. The notion of a geographically based community, constituted in recognition of common identity, interests, and obligations, gives way to an "ego-based" or "personal network" construction of community. In this construction, a social network, one's community, is not a shared public good held by all in common, but a private asset, a personal store of social capital actively built and maintained by individuals to suit their own individual sense of identity, desires, needs and interests.

And it follows from this that networked relations are distributed differentially rather than uniformly. That is, some individuals establish and maintain stronger community relations than others, and some individuals establish very few, and are socially isolated (see Fig. 7).

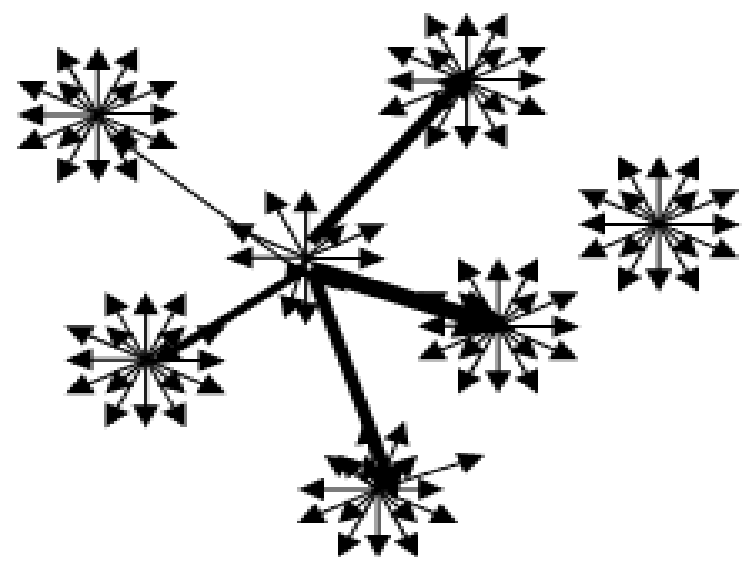

Fig. 7: community connections occur differentially. 
It is interesting to note that links between actors in the network are not uniformly distributed, but, in the formal terms of network mathematics, the links follow "power laws" and are "scale free" (Barabási, 2002). Whilst Figure 5 implies a network architecture that is roughly egalitarian, in that links are randomly or uniformly rather than preferentially distributed, the lessons of power laws are immanent in Figure 7. In simple terms, power laws seek to model the fact that network links are highly clustered, not evenly distributed. In the case of the Internet as a whole for example, in a sample of 203 million web pages, $90 \%$ had 10 or fewer links pointing at them, whilst a few were referenced by close to one million other pages (Barabási, 2002). According to a maxim familiar to many in the Community Network project, the rich get richer, whether the currency is money, web page connections, or community resources. If this were not the case we would expect that the community connections in any given population would follow other normally distributed phenomenon, where most individuals have similar numbers of links, and where only a few are extremely high or extremely low. (see Fig. 8)

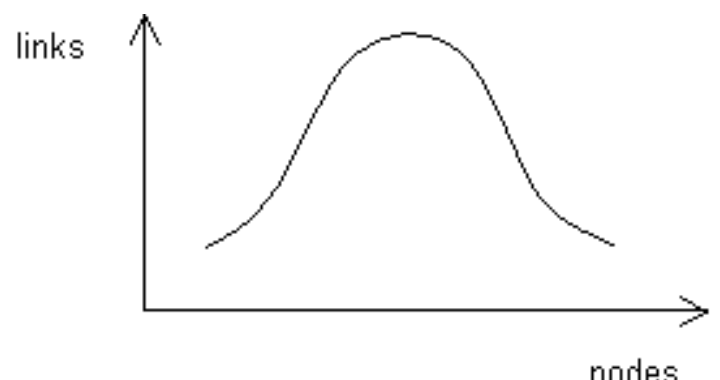

Fig. 8 a normal distribution

But this is not the case in scale-free networks, where power laws predict that a few nodes will have a great many links, whilst most nodes will have very few (see Fig. 9).

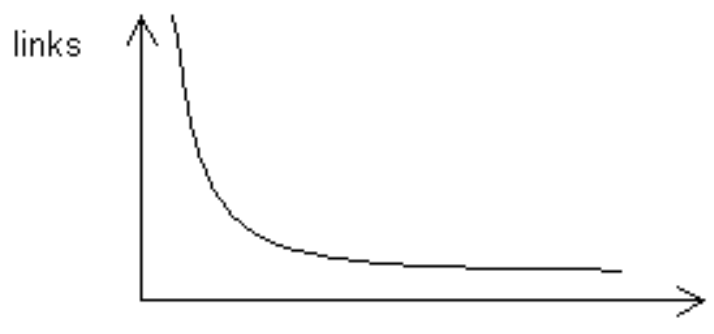

Fig. 9 a power law distribution

nodes

This representation of community networks as private assets has little in common with traditional representations of community, and little in common with the conceptualization of community implied by the Community Network project.

The rise and rise of individualism as a political resource, and the actions of the market as the arbiter of societal relations - now read as relations between individuals - has done terrible damage to other named groupings such as Society, Union, Class, Neighbourhood, Gender - even Nations, Races and Religions. In many first-world, post-war societies, these forms of defined collective interest have been subject to sustained criticism. First the Left and more recently the New-Right or "neo-cons" have argued positions which attacked public or communal activity on the grounds of both efficiency and legitimacy (Kumar, 1992), and in the 1980's in particular, the withdrawal of "the public good" as a target for social policy was speeded by a neo-conservative, New-Right or economic rationalist ideological hegemony. The popular ethos over this time has been to increasingly demand private consumption, mediated through the market, for the satisfaction of personal rather than communal ideals or objectives (McLean \& Voskresenskaya, 1992). The public institutions and public utilities established in the last half of the 19th century and the first half of the 20th century to provide education, power, health services, transport, communications and so on, were informed and constituted by a modernist discourse which centred on the virtues of centralised decision-making, public service, public good and public responsibility. These have in recent times become increasingly fragmented, decentralised, privatised, self-managing and entrepreneurial, and are redefining their mission in ways which do not privilege broadly conceived social good, except as a derivative of market performance. Institutionalised social relations have thus been reconstituted around a discourse that valorises private benefit, individual responsibility and consumer sovereignty. In the sphere of personal social relations the individual is no less privileged, and constructions of needs, rights, desires, responsibilities, tastes, and opinions are all read as attributes of individual agency. Digital technologies are of course deeply implicated in the construction of this changed ground. We build our own community networks, and within these networks obligation and reciprocation coexist, often uneasily, with individualism - which remains the dominant mode of relations. Indeed, "[n]o longer do we, as members of the group, belong to the community, rather the community belongs to us." (Jones, 1997)

Yet "community", read ontologically as Gemeinschaft, is often called upon to serve ideological and rhetorical purposes, where other collectives or named groupings are not. 


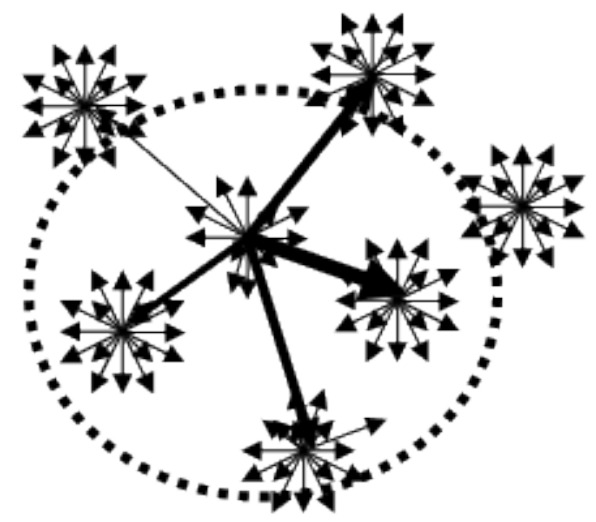

Fig 10: community as a bounded network

At a policy level, and in terms of contemporary ideology, a Community Network may be represented as a bounded collection of "ego-based" social networks. A Community Network is bounded in so much as the not-for-profit collective or the property developer "scopes" the Community Network, and defines its target market. A Community Network project creates a group, makes provision for an infrastructure, limits ramified access by creating boundaries, presents the group space as an ongoing default for all, founded on the objectivity of shared conditions. Thus community as a linked group, as communal infrastructure, is rescued as a research focus, a context for practice, a policy objective, and as an ontological being. At the same time though, the Community Network is recognised in individual action, in distributed social performance, and in a multitude of private assets. The modernist Community Network project is thereby consistent with the 50 year political drift from public service, funded by the taxpayer, and provided through central governmental agencies, to the position that devolves service provision to the private and non-profit sectors, and asks that people and communities bootstrap their own way out of their difficulties through the limited infrastructure provided.

Meredith, Ewing and Thomas make the point very well in their study of an Australian neighbourhood renewal project, and its implications for governance (Meredith, Ewing, \& Thomas, 2004). The authors remind us that the shift away from the central role of state agencies and professionals to community groups, volunteers and not for profit groups is a new response to an old problem of legitimising governance. The modernist state is founded on rationality, and needs to provide conditions of prosperity and security, at least at certain minimum levels. This in turn, requires it to penetrate and assert influence over civil domains that are beyond its immediate reach - commercial, familial, domestic and social domains.

Last century's answer to this challenge was the school, the hospital and the prison provided by the State, and this century's answer is the Community Network we build ourselves. Systems of education, health, electrical power, water, transport, and justice were all envisaged as common social infrastructure - in a sense, as scaled networks accessible to all (except perhaps at the extremes) - and thus exercising an egalitarian and commonly civilizing influence. Arguably though, the education system has operated as a vehicle for the creation and expression of social differentials, and arguably, its patterns of access and benefit are better described by power laws than by normal distribution. Though they don't use these terms, Graham and Marvin have reached similar conclusions in respect of water, transport and other infrastructures (Graham \& Marvin, 2001).

By highlighting these modernist binaries - events in time and space, networked individuals and grouped community, nodes and links, performance and structure - and by pointing to both ends of the binary rather than seeking to reconcile or arbitrate between them, the a-modern approach is able to pursue the sort of critical analysis illustrated above. And even if the reader does not consider the critique to be powerfully persuasive, it may be allowed that the approach opens up ground for the construction of analysis that has the potential to be powerful and persuasive.

\section{The Hierarchic and the Heterarchic}

Whilst a Community Network articulates and hybridises the contradictions of the social and the technical, the community group and the networked individuals, an a-modern approach reveals that it similarly articulates and hybridises hierarchy and heterarchy. It is the material arrangements, the technical mediation of the social interaction that is hierarchical, whilst the social arrangements emergent through this technical mediation give rise to heterarchy.

Electronic space is meticulously structured in a detailed and rigorously hierarchical fashion. Flows of digital signals have a structure determined at various levels, from the deeply embedded structures of logic gates, to operating systems and machine-language architecture, to the surfaces of interface design. In this sense digital flows can be said to have a material character that Ostwald (following Deleuse and Gualtieri) calls the "arborescent schema" (Ostwald, 1997). High modernist architecture, modernist organizational and management theorists, and the designers of many computer environments share this common conceptual framework, whereby the world is represented as an inverted tree or semi- 
lattice structure which is hierarchical (rather than say, rhizomatic), and is binary rather than analogue (see Fig. 11).

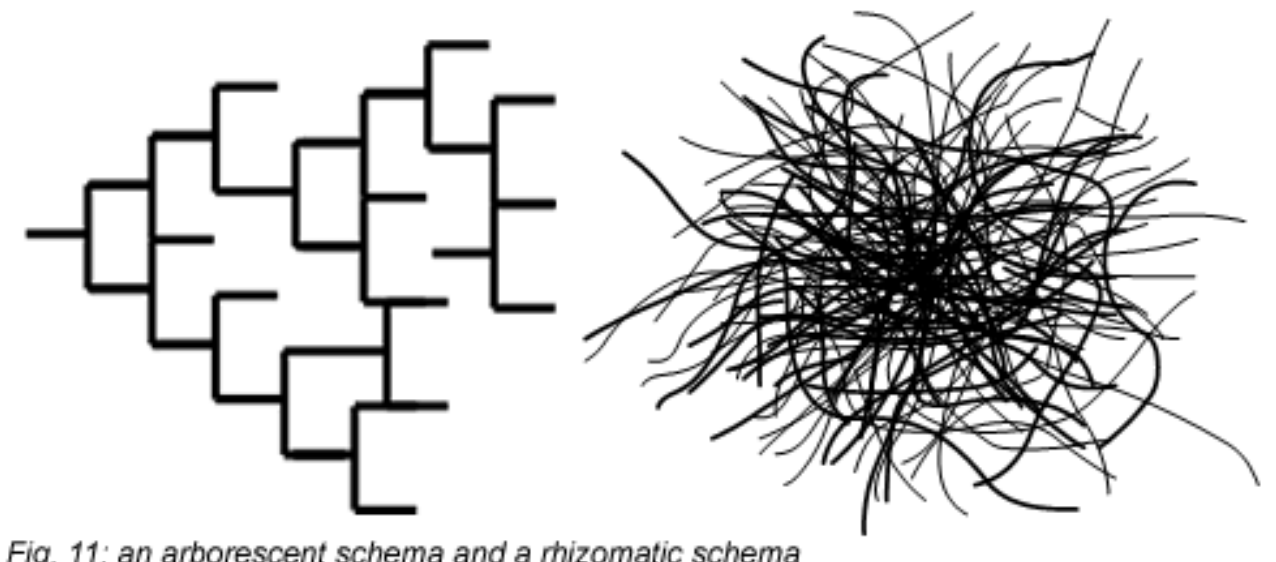

Fig. 11: an arborescent schema and a mizomatic schema

An arborescent schema is a form of power that functions by situating its constituent entities in hierarchical relation to one another, some near the trunk, others out on the edge, and in so doing, positions subjugation and domination. As Ostwald argues, arborescent structures are subject to critical attack. They manifest a desire to discipline movement and location on the basis of a reductionist categorisation embedded in the very structure of the space inhabited by people, or data. In Bogue's words

“Arborescences are hierarchical, stratified totalities which impose limited and regulated connections between their components. Rhizomes, by contrast, are non-hierarchical, horizontal multiplicities which cannot be subsumed within a unified structure, whose components form random, unregulated networks in which any element may be connected with any other element." (Bogue 1989, p.17)

In the case of the Internet for example, the expression of a will to power that suffuses latent arboreal structures is evident at a number of levels. At the global level Google, Myspace, Microsoft, Yahoo, Amazon and company, occupy a position near the centre of the "Bow Tie" (Broder et al., 2000), on the main trunk of the arboreal structure. These companies are thus passage-points for huge volumes of electronic traffic, and potentially discipline that traffic by structuring the "space of flows" from there. At the other extreme, one might take a point far out on the extremity, where the leaves of the tree consist of, say, postings on a Community Network site. These too are subject to the discipline of an arboreal structure where lateral links are problematic, and each post is an appendage of the node to which it is attached, which in turn has its place on the hierarchy. Postings and web pages neither exist on their own terms (but in hierarchical connection to other nodes and pages) nor on interdependent terms (as say, a latice of equally connected contributions).

An online discussion conducted via email for example, is the hierarchically structured, serial exchange of textually expressed monologues and a "Bulletin Board" type of on-line discussion makes the arborescent hierarchy clear in its graphical representation of threads. As a network of postings it is scale-free and follows power laws. In rough terms therefore, (as any subscriber will confirm), $20 \%$ of participants make $80 \%$ of postings, and $20 \%$ of postings attract $80 \%$ of responses, while $80 \%$ of postings just sink without trace, and drift in cyberspace unread and unanswered, like notes in bottles, floating on the sea (Holmes, 1997).

In addition to being clustered, listservs and discussion groups display a valence for order and discipline in so much as they define and bound areas of social interest. Each discussion group is a branch, usually organised around a quite narrow topic, stemming from a larger branch supporting many narrow topics, stemming from a still larger branch, all the way to a handful of main topic categories. Ostwald aptly describes this arrangement as bureaucratic; as an isomorph for the space of social interaction, it arguably fails, and it is difficult to characterise it as a space convivial to community primitives as traditionally conceived, though it is quite consistent with community relations as private social assets.

Social relations in such an ordered space are goal-oriented, purposeful, and disciplined by the space as well as the social norms of the group, such that our presence in the same discussion group has something of an instrumental character about it. I may be interested in fish and may converse with you on rec.aquaria.freshwater in a hobby centre in a Community Network, but it is the Guppies I'm interested in, not you. On WilliamstownOnLine/GoodBuys it is the price of the coffee and the quality of the fruit that is interesting, not you. In contrast, when we meet at the tram-stop and exchange words about fish tanks and fruit, it is not the fish tanks and fruit that is at the heart of the exchange, it is the exchange itself. The social exchange is phatic, not instrumental. The exchange involves a "transcendence", a "besideeach-otherness" (Jones, 1997), which takes it beyond its subject matter or informational content. In the world of ICTs the space of social relations is ordered, rational, ruled - reflecting a heritage and an architecture that is inspired more by Le Corbusier's Stalinist fantasies than the Toennesian fantasies of the village green, or Habermas' coffee house. The space that was designed for calculation, data-storage, file transfer and remote computer use then became a space for the management of a work-force, the transfer of funds, and the commercial exchange of goods and services, and is now a space for communities. 
So, a Community Network shares hierarchy with its digital cousins and ancestors, but, as I shall argue, its sociotechnology also gives rise to heterarchic arrangements.

The conceptual foundations for the notion of a heterarchy were laid down in the natural sciences and in management theory (Grabher \& Stark, 1997), and have since found wider application. Unlike a hierarchic system which rises to a single point, has a single trajectory, or equilibrium, or centre of gravity, (depending on the preferred metaphor) a heterarchic system has many such points (Grabher, 2001; Grabher \& Stark, 1997). Rather than a single trunk in a hierarchical tree structure, a heterarchy is rhyzomatic, and has a number of points that act as centres. In the case of a Community Network, these clusters of circulation may be individuals, projects, or issues, for example. Each is at the centre of the whole system for the actors that circulate around it - and there is therefore more than one point of circulation in any given system. A heterarchy is a self-organizing, autopoietic system, and the centres of action are emergent in action, not established structurally. It $i s$ what it does, and what it does is structurally underdetermined (see Fig. 12).

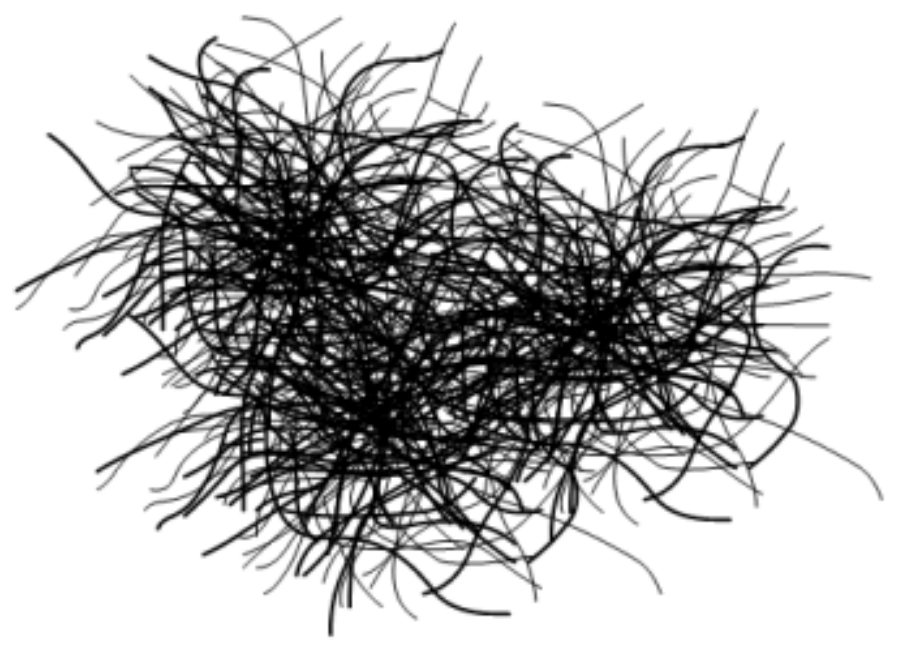

Fig. 12: a heterarchy

In these circumstances, where centres of social action, resourcing, and decision-making are multiple, the balance between integrative and disintegrative processes, between conditions of stability and instability, is fine. Heterarchies are characterized by high tolerance for diversity, evident in the presence of multiple centres, and provided by the presence of multiple centres. This plurality allows resources to be devolved rather than concentrated; it allows energies and actions to head in different directions simultaneously; and it allows different priorities, objectives and strategies to coexist. But as (Grabher, 2001) asks, how much inefficiency can the aggregation of centres tolerate for the sake of adaptability and heterogeneity, without sacrificing capacity for production?

These tensions between the relative efficiency and stability of a "top down" hierarchy, and the "bottom-up" groundedness and flexibility of a self-organizing heterarchy, are played out in the sociotechnical space created by Community Networks. Policy makers, local governments, funding agencies, ICT system designers and Community Network coordinators have a "top down" interest in stability, coherence and efficiency across the system, whereas users, community activists and local groups have a "bottom up" self-defined interest. Holding on to this binary and playing out the tensions that emerge is one manner in which the Community Network shapes itself, and is one manner in which it can be understood, rather than privileging one over the other. Each must be embraced simultaneously.

\section{Conclusion}

To get a grip on a Community Network as a social-technical, network-community, hierachic-heterarchic hybrid, is to focus an assessment on the hybridity itself. That is, the implications of the Community Network flow from the reflexivity of binaries - not from the effects of either one separately, or the effects of both in parallel; rather it flows from the hybrid "monster" (John Law, 1991) that emerges from a conflation of the two. A Community Network is not (technical and network and hierarchic), or (social and community and heterarchic), and is not in some respects one, and in other respects the other; in some contexts one, and in other contexts another. Rather it is in all respects a hybrid, in so much as the social/technical, network/community, and heterarchy/hierarchy are codependent in the same system.

So, a community Network should not be theorised exclusively in terms of a technology that moves a society towards a good, or as a society moving technologies towards a good. If seen as a hybrid, everything changes - including what is good. Moreover, a Community Network should not be theorised as a public good infrastructure supporting Gemeinschaft community. In an important sense a Community Network is a resource for building private assets.

Further, a Community Network should not be theorised as hierarchical, (though its sociotechnical structure is), nor should it be seen as heterarchical, (though its sociotechnical structure is). Rather, its peculiar characteristics arise from 
both.

This a-modern theoretical strategy does not lead to a simple answer - either utopian, dystopian, or in the middle. Instead, it argues that a Community Network, like all technologies, enframes the world: that is to say, it does not answer this or that question, satisfy this or that demand, extend this or that capacity. Rather, technologies such as Community Networks work at a more fundamental level; they enframe the world such that the question is changed along with the answer, the need is changed along with its gratification, and direction is changed along with the mechanism. The calculator or the word processor, are not more effective, efficient or convivial methods of doing mathematics or writing - they change what it is to do mathematics or to write. The Internet does not provide a more efficient way of doing the same things - it does different things.

A Community Network is not just a means of meeting desires, it also changes the cultural, social, economic and emotional frames that give rise to desire, and situate desire. A Community Network is thus metaphysical, and not simply instrumental, or technical, or social, or hierarchical, or heterarchical.

\section{References}

Arnold, M. (2002). Key4Building meets Habermas, Foucault and Latour. In S. A. Clarke (Ed.), Socio-Technical and Human Cognition Elements of Information Systems. Hershey, PA: Idea Group Publishing.

Arnold, M. (2003). Intranets, Community, and Social Capital: The Case of Williams Bay. Bulletin of Science, Technology \& Society, 23(2), 78-87.

Arnold, M., Gibbs, M., \& Wright, P. (2003). Intranets and the Creation of Local Community: 'Yes, an intranet is all very well, but do we still get free beer and a barbeque?' In M. Huysman, E. Wenger \& V. Wulf (Eds.), Communities and Technologies. Dordrecht, Boston, London: Kluwer Academic Publishers.

Barabási, A.-L. (2002). Linked : the new science of networks. Cambridge, Mass.: Perseus Pub.

Bogue, R. (1989) Deleuze and Guattari. London: Routledge.

Broder, A., Kumar, R., Maghoul, F., Raghavan, P., Rajagopalan, S., Stata, R., et al. (2000). Graph structure in the web. Retrieved Feb, 2004, from http://www.almaden.ibm.com/cs/k53/www9.final/

Clement, A., Gurstein, M., Moll, M., \& Shade, L. (2003). Canadian Research Alliance for Community Innovation and Networking. Retrieved June, 2004, from http://www.fis.utoronto.ca/research/iprp/cracin/CRACIN.pdf

Grabher, G. ( 2001). Ecologies of creativity: the Village, the Group, and the heterarchic organisation of the British advertising industry. Environment and Planning A, 33(2), 351 - 374.

Grabher, G., \& Stark, D. (1997). Organizing Diversity: Evolutionary Theory, Network Analysis and Post-Socialism. In Gernot Grabher \& David Stark (Eds.) Restructuring networks in post-socialism : legacies, linkages, and localities. Oxford: Oxford University Press.

Graham, S., \& Marvin, S. (2001). Splintering urbanism : networked infrastructures, technological mobilities and the urban condition. New York: Routledge.

Holmes, D. (1997). Virtual Identity: Communities of Broadcast, Communities of Interactivity. In D. Holmes (Ed.), Virtual Politics: Identity and Community in Cyberspace (pp. 26-45). London - Thousand Oaks - New Delhi: SAGE Publications.

Jones, S. G. (1997). The Internet and its Social Landscape. In S. G. Jones (Ed.), Virtual culture : identity and communication in cybersociety (pp. 7-35). London: Sage Publications.

Kumar, K. (1992). New Theories of Industrial Society. In Brown \& H. Lauder (Eds.), Education for Economic Survival: from fordism to post-fordism? London and New York: Routledge.

Latour, B. (1993). We have never been modern (C. Porter, Trans.). New York: Harvester Wheatsheaf.

Latour, B. (1999). Pandora's hope : essays on the reality of science studies. Cambridge, Mass.: Harvard University Press.

Law, J. (Ed.). (1991). A Sociology of monsters : essays on power, technology, and domination. London ; New York: Routledge.

Law, J., \& Hassard, J. (Eds.). (1999). Actor Network Theory and After. Oxford: Blackwell.

McLean, M., \& Voskresenskaya, N. (1992). Education Revolution from Above: Thatcher's Britain and Gorbachev's Soviet Union. Comparative Education Review, 36(1), 71-90.

Meredith, D., Ewing, S., \& Thomas, J. (2004). Neighbourhood Renewal and Government by Community: The Atherton Gardens network. The International Journal of Cultural Policy, 10(1). 
Ostwald, M. J. (1997). Virtual Urban Futures. In D. Holmes (Ed.), Virtual Politics: Identity and Community in Cyberspace (pp. 125-144). London - Thousand Oaks - New Delhi: SAGE Publications.

Pollner, M. (2002). Inside the Bubble: Communion, Cognition and Deep Play at the Intersection of Wall Street and Cyberspace. In S. Woolgar (Ed.), Virtual Society? Technology, Cyberbole, Reality (pp. 230-246). Oxford: Oxford University Press.

Rheingold, H. (1993). The Virtual Community: homesteading on the electronic frontier. Reading, MA: Addison Wesley.

Sherman, C. (1999). Local Connections: Making the Net Work for Neighbourhood Renewal. Unpublished manuscript, London.

Webster, F. (1994). What Information Society? The Information Society, 10, 1-23.

Webster, F. (1995). Theories of the information society. London and New York: Routledge.

Wellman, B. (Ed.). (1999). Networks in the Global Village. Boulder, Colorado: Westview press.

Wellman, B., \& Haythornthwaite, C. (Eds.). (2002). The Internet in Everyday Life. Oxford: Blackwell Publishing.

Winner, L. (1993). Upon Opening the Black Box and Finding it Empty: Social Constructivism and the Philosophy of Technology. Science, Technology and Human Values, 18(3), 362-378.

Wise, J. M. (1997). Exploring Technology and Social Space. Thousand Oaks: Sage Publications. 